\title{
A productivity analysis considering environmental pollution and diseases in China
}

\author{
Huijuan Cao ${ }^{1}$, Hidemichi Fujii ${ }^{2}$ and Shunsuke Managi ${ }^{3,4^{*}}$
}

\author{
* Correspondence: \\ managi.s@gmail.com \\ ${ }^{3}$ Global Environmental Engineering \\ Program, School of Engineering, \\ Kyushu University, 744 Motooka \\ Nishi-ku, Fukuoka 819-0395, Japan \\ ${ }^{4}$ Queensland University of \\ Technology, Level 8, Z Block, \\ Gardens Point, 2 George St, \\ Brisbane QLD 4000, Australia \\ Full list of author information is \\ available at the end of the article
}

\begin{abstract}
Environmental pollution and human health problems are becoming serious issues in China. This research focuses on regional differences in productive inefficiencies and attempts to clarify the determinants of inefficiency, accounting economic, environmental and health-related factors. Our dataset includes information of 29 areas in China from 2003 to 2009. We find that after accounting for environmental pollution and health impacts, the productive inefficiency of the examined areas reduced; this result holds for both the national and provincial levels. Our results imply that government efforts to improve social welfare should emphasize increases in foreign direct investment and private medical expenditures.
\end{abstract}

JEL codes: 115, O44, O47, R11

Keywords: Environmental pollution; Disease; Regional disparity; China; Weighted Russell directional distance function

\section{Background}

Over the previous three decades, China has achieved dramatic economic development. However, this growth has been characterized by alarming and sometimes hidden imbalances in development across different provinces, between rural and urban regions, and even among areas within the same province [1]. Due to their different physical geography and population characteristics, the central and western regions of China have fallen behind the eastern region with respect to both economic and social development. This gap has particularly widened since the 1990s. Moreover, foreign direct investment (FDI) provides tremendous contributions to development [2].

Environmental pollution is also becoming a serious social issue in China. This pollution is related to rapid industrial growth, and the main pollutants are waste gas emission and wastewater discharge [3, 4]. Air pollution causes damage to a variety of aspects of human health (e.g., the cardiovascular, respiratory, and immune systems) and increases the risk of lung cancer and adverse birth outcomes [5].

Water pollution is also related to damage to human health. Drinking water with high concentrations of bacteria will increase the risk of infectious diseases (e.g., cholera and dysentery). These diseases are more common in poor rural regions of China, due to the lack of water sanitation in these areas. Data from the National Bureau of Statistics 
of China and the Chinese Ministry of Health indicate that $40 \%$ of rural residents and $62 \%$ of urban residents in China may be exposed to significant risks of infectious disease due to unsafe drinking water. Furthermore, wastewater that has been contaminated by industrial pollutants may produce cancers of the digestive system (e.g., stomach, liver, esophagus, and colorectal cancers). Although the size of the population affected by this type of water pollution is unknown, based on data from the Chinese Ministry of Health, it is estimated that $11 \%$ of total digestive system cancer cases are caused by industrial water pollution. In other words, wastewater treatment systems play an important role in environmental and health considerations.

Since China adopted its "reform and opening up" policy in 1978, its medical care system and the health of its residents have rapidly improved. In 1978, despite its lowincome conditions, China underwent its first health revolution. The changes of this revolution focused on public medical care services, particularly water sanitation improvement and medical insurance [6]. However, China's experience demonstrates that economic growth alone does not generate health improvements for all [1]. Similarly to economic growth, human health status is also characterized by regional disparities. Individuals from relatively poorer regions with worse overall living conditions lack safe drinking water, health care information, and the ability to engage in private medical care expenditures and hospital access. Furthermore, poor living conditions are associated with higher risks of infectious diseases, such as cholera, dysentery and measles.

Because it recognizes that public health plays an important role in improving social welfare, the Chinese government has made the protection of health and safety one of its foremost priorities, particularly since the SARS crisis of 2003 [1]. The Disease Emergence and Notifiable Infectious Disease Reporting System began operating in China at the end of 2003. The government's overall investment in health care has increased, and public health and clinical service delivery systems are being developed in both urban and rural areas.

Additionally, the "Go West" policy has focused on promoting development in the western region of China with greater levels of support from the central government, and the New Rural Cooperative Medical System has been introduced [7]. Furthermore, the China People's Daily published an article entitled "Report of local government and official performance evaluation in China" in 2008, which indicated that other important factors in addition to the GDP should be used as measuring indices. There are several indicators to measure the performance of local government. For example, harmony of the society, work ethic and morality, environmental quality, etc. [8].

Health damage can also be measured in terms of economic losses. Kira et al. [9] demonstrated that air pollution has created a substantial socioeconomic burden for China's economy. They considered the losses in consumption and social welfare which were produced by health damage from air pollution. In particular, they considered health damage in terms of morbidity and mortality. Additionally, according to Kan and Chen [10], in Shanghai, total economic cost of health impacts due to air pollution was 625.40 million US dollars in 2001, accounting for $1.03 \%$ of gross domestic product of that city.

Furthermore, medical cost due to health problems also leads to productivity loss. According to neoclassical economic theory, the concept of productivity is based on the production function, where output is a function of capital and labor input. Productivity is a measure of output per unit of input. Labor input reflects the quantity (e.g., time) 
and quality (e.g., effort and skills) of the work force. Productivity loss due to health problems refers to the output loss corresponding to the reduced labor input due to health problems [11].

Economic growth, better environmental conditions, and improved public health will improve social welfare. Therefore, policymaking should not only focus on economic growth but also address environmental protection and public health preservation. We focus on these three areas of interest: economic, environment, and health. This research paper is unique in that there is no previous study that simultaneously considers all three of these fields. In step 1 of this study, to measure social welfare, we estimate the productive inefficiency in each area of China, considering both environmental pollution and disease. We also seek to estimate the individual inefficiency scores of specific social welfare indicators, including economic growth, environmental pollution, and disease. In other words, we attempt to simultaneously estimate both the maximum expansion of the economy and the maximum reduction in pollution emissions and disease cases. In step 2 of this study, we attempt to identify exogenous factors for improving social welfare by creating a better living environment and health conditions. On the whole, we will estimate the major influences on aggregate productive inefficiency and the individual inefficiency of different social welfare indicators.

This research focuses on regional differences in productive inefficiency and clarifies the determinants of this inefficiency. In particular, economic, environment, and health considerations are addressed. This investigation is accomplished through the use of provincial data for 29 areas in China from 2003 to 2009.

There are previous studies of economic, environmental, and health issues in China, as discussed below. However, it is difficult to find any research that simultaneously addresses all three of these fields. Nan and Gao [12] observe that environmental pollution has become an important constraint on China's economic growth and that high levels of energy consumption are an important driver of environmental pollution.

Kan et al. [13] suggest that a consideration of the health impacts of air pollution, which is associated with fossil fuel use, can facilitate progress towards sustainable development. Similarly to Kan et al. [13], many other studies also explore the links between air pollution and public health. In particular, to addressing the short-run connections between these topics, a number of daily time-series and case-crossover studies have been conducted in large Chinese cities, including Beijing, Shanghai, Chongqing, Shenyang, Wuhan, and Anshan [13]. However, only one published air pollution cohort study has examined the long-run connections between air pollution and public health in China [14].

Liu and Griffiths [1] reveal the relationship between economic development and public health and discuss a series of issues that relate to health disparities. In particular, they offer the following claims. (1) In China, regional disparities contribute to problems with human health. (2) Poor living conditions are associated with a higher risk of contracting infectious diseases, such as cholera, dysentery, and measles. (3) Private medical expenditures fell by $19 \%$, and private spending on critical illnesses decreased by $36 \%$ after the enrollment of Chinese citizens in the New Cooperative Medical Scheme, which began in 2003 and sought to include all Chinese residents by 2010 .

Additionally, Kan and Chen [10], estimate the total economic cost of health impacts due to particulate air pollution in urban areas of Shanghai in 2001. The result shows that it is approximately 625.40 million US dollars, accounting for $1.03 \%$ of gross domestic product of the city. They suggested that the impact of particulate air pollution 
on human health could be substantial in urban Shanghai, both in physical and economic terms. In this research, the health outcomes are estimated for number of disease cases associated with air pollution.

Furthermore, Lybarger et al. [15] estimate the expected medical costs as economic loss and the average costs of productivity loss, which are associated with volatile organic compounds in drinking water in the US. In this research, lost productivity is accounted for the work time loss while obtaining inpatient or outpatient care.

Several research papers examine whether education has a positive or negative effect on economic growth. The results of these studies are dependent on the specific situation. Zhang and Zhuang [16] demonstrate that only the average number of years of schooling produces a positive effect on economic growth in China. Other factors, such as the literacy rate and the enrollment rate in higher-level education, are not statistically significant drivers of economic growth. Furthermore, Zhang and Zhuang [16] also show that in relatively rich areas of China (most of which are in eastern China), higher education (i.e., a college education) produces a stronger effect on economic growth. By contrast, in relatively poor areas (which are mostly in western China), lower-level education (i.e., a primary education) generates a stronger effect on economic growth.

Sanjeev et al. [17] demonstrate that in developing countries, education level positively affects public health. In particular, increases in the adult literacy rate produce sharply lower infant and child mortality rates and less dramatic reductions in total mortality rates. Furthermore, increased public medical expenditures as a share of GDP also generate reductions in infant and child mortality. However, only a weak relationship exists between medical expenditures and the mortality rates of the entire population.

A number of research papers conclude that poverty and income levels have relatively strong impacts on health care, whereas changes in public medical expenditures produce a relatively weak impact on this issue [18]. In other words, stronger impacts on human health are generated by private medical expenditures than by public medical expenditures.

Additionally, Lauter and Moreaub [19] pointed out that FDI attraction has become a priority of development agendas in developing country. Development strategies used to focus on state's investments and interventions; FDI is now considered as the main source of catching-up and technological development. Wang et al. [20] use panel data from 287 Chinese cities over the period 1999-2005 and assess the multiple impacts of FDI in both positive and negative domains. They conclude that FDI enhances economic growth, labor productivity, and innovation but also causes employment reduction and environmental pollution. To measure pollution intensity of a city, they use data of total factory $\mathrm{SO}_{2}$ emission divided by land area (tons/square kilometer), based on the reports by China's environmental protection agency.

To achieve our research aims, we offer the following three hypotheses, which are based on the results of various previous studies.

(H1) FDI may negatively affect productive inefficiency but may positively affect inefficiencies that are associated with emissions of waste gas and wastewater.

(H2) Investments in pollution abatement may negatively affect the inefficiencies that are associated with waste gas and wastewater.

(H3) Private medical expenditures may negatively affect the inefficiency levels of various types of patients and infectious diseases. 


\section{Methods}

\subsection{Weighted Russell directional distance model}

In a social system, labor and capital can be considered to be inputs. These inputs are used industrial production which cause environmental pollution and diseases directly or indirectly. Economic growth can be regarded as a desirable output, whereas environmental pollution and diseases could be regarded as undesirable outputs that are related to economic growth. As mentioned above, measurements of social welfare should not only focus on the desirable output of economic growth but also account for the undesirable outputs of environmental pollution and disease. Therefore, high social welfare would be associated with high economic output, low levels pollution and disease, and lower use of labor and capital.

Due to the regional disparities across different areas in China, data for the entire country may be misleading. Therefore, individual measurements of each area are required. To establish a goal for improving welfare, we should define the "best" area(s) that lie on the frontier line and then compare each area with the frontier line. Therefore, comparative measurements across different areas are also required. Productive inefficiency analyses that simultaneously consider multiple inputs and outputs are indicators of social welfare. Thus, comparative productive inefficiency analyses may be used to assess a number of evaluation targets over a specified time period. The result can demonstrate changes in productive inefficiency shifting during the examined time. These changes indicate deteriorations or improvements in overall welfare.

Aggregate productive inefficiency and the individual inefficiency of each input/output can also be simultaneously presented. Because measurements of aggregate productive inefficiency require comparative analysis, they indicate how an area is performing with respect to welfare relative to the highest level of welfare in China. Furthermore, individual inefficiencies in inputs/outputs emphasize the specific goals for welfare improvement, which are the expansion of economic growth and the reduction of environmental pollution and disease. In accordance with Barros et al. [21] and Fujii et al. [22], the current study utilizes weighted Russell directional distance model (WRDDM) to measure productive inefficiency through nonparametric linear programming estimations. As Barros et al. [21] observe, one important advantage is that WRDDM can simultaneously individually decompose the inefficiency scores of each element of a set of multiple inputs/outputs.

Suppose there are $j=1,2, \cdots, k, \cdots, J$ decision making units (DMUs) in the dataset, with one DMU for each area in China. Each DMU uses inputs $x=\left(x_{1}, x_{2}, \cdots, x_{N}\right) \in R_{+}{ }^{N}$ to jointly produce the desirable outputs $y=\left(y_{1}, y_{2}, \cdots, y_{M}\right) \in R_{+}{ }^{M}$ and the undesirable outputs $b=\left(b_{1}, b_{2}, \cdots, b_{L}\right) \in R_{+}{ }^{L}$. WRDDM for calculating the inefficiency of DMU $k$ can be described as follows:

$$
\vec{D}(x, y, b \mid g)=\operatorname{maximize}\left(\frac{1}{N} \sum_{n=1}^{N} \beta_{n}^{k}+\frac{1}{M} \sum_{m=1}^{M} \beta_{m}^{k}+\frac{1}{L} \sum_{l=1}^{L} \beta_{l}^{k}\right)
$$

subject to the following conditions:

$$
\begin{aligned}
& \sum_{j=1}^{J} z_{j} y_{m j} \geq y_{m k}+\beta_{m}^{k} g_{y m k} \\
& \sum_{j=1}^{J} z_{j} b_{l j}=b_{l k}+\beta_{l}^{k} g_{b l k}
\end{aligned}
$$




$$
\begin{aligned}
& \sum_{j=1}^{J} z_{j} x_{n j} \leq x_{n k}+\beta_{n}^{k} g_{x n k} \\
& z_{j} \geq 0, \quad j=1,2, \cdots, k, \cdots, J
\end{aligned}
$$

where $\beta_{m}^{k}, \beta_{l}^{k}$, and $\beta_{n}^{k}$ are the individual inefficiency scores of each desirable output, undesirable output, and input, respectively. In the relationships above, $z_{j}$ is the intensity variable that is used to determine the frontier line, which consists of all of the DMUs (i.e., each area). We set the directional vector $\left(g_{x n k}, g_{y m k}, g_{b l k}\right)=\left(-x_{n k}, y_{m k},-b_{l k}\right)$ to estimate productive inefficiency. This type of directional vector assumes that an inefficient area can decrease its productive inefficiency by increasing its desirable outputs and/or decreasing its undesirable outputs and inputs [23].

\subsection{Panel tobit model}

The productive inefficiency scores that are estimated by WRDDM from pooled data (i.e., the pooled WRDDM) will be used as dependent variables in a panel tobit model to identify the external factors that contribute to decreasing each type of inefficiency score. Panel tobit model can be used to measure the effects of external factors. The principal objectives of this analysis are to measure productive inefficiencies and identify the external factors that may be related to productive inefficiency. The productive inefficiency scores from the pooled WRDDM in step 1 of the analysis are used as dependent variables in the panel tobit model in step 2 of this analysis.

The panel tobit model represents a situation in which the dependent variables are censored and limited. This condition is important in the context of this study because almost all of the inefficiency scores (ISs) lie between 0 and 1 . In the panel tobit model, this study used 1-year lags of investment as its independent variables $(X)$. This assumption allows for a 1-year time lag between an investment and its impact.

$$
\begin{aligned}
& \mathrm{IS}_{i t}^{*}=\beta_{0}+\beta X_{i(t-1)}+\eta_{i}+\mu_{t}+\varepsilon_{i t} \\
& \mathrm{IS}_{i t}=\mathrm{IS}_{i t}^{*} \quad \text { if } 1 \geq \mathrm{IS}_{i t}^{*} \geq 0 \\
& \mathrm{IS}_{i t}=0, \quad \text { otherwise }
\end{aligned}
$$

\subsection{Data}

The main variables that are used in the analysis are gross regional product (GRP) as the desirable output, labor (number of workers) and capital stock as inputs, and the quantity of wastewater discharge, quantity of waste gas emissions, number of patients, and cases of infectious diseases as the undesirable outputs (see Table 1). For the productive inefficiency calculation, we use panel data at the provincial level. These data represent 29 different areas of China. All of the financial data variables are deflated to 2005 price levels.

1. Labor: To represent labor, we utilize the number of workers in three sectors (agriculture, industry, and service). These data are available in the China statistical yearbook (CSY) for all sample years except 2006. Therefore, in this research, labor in 2006 is estimated by the authors based on labor data from comprehensive statistical data and materials on 60 years of new China (CSDM60). These data are multiplied by a coefficient of $0.962 .^{1}$ 
Table 1 Summary of variables for WRDDM in step 1 among 29 areas, from 2003 to 2009

\begin{tabular}{|c|c|c|c|c|}
\hline \multirow{2}{*}{$\frac{\text { Variable name }}{\text { Labor }}$} & \multicolumn{2}{|c|}{ Description of variables } & \multirow{2}{*}{$\frac{\text { Mean }}{2,396}$} & \multirow{2}{*}{$\frac{\text { St. d. }}{1,548}$} \\
\hline & Definition & $\begin{array}{l}\text { Labor of } 3 \text { sectors (agriculture, industry, } \\
\text { and service sector) }\end{array}$ & & \\
\hline & Unit & 10 thousands of person & & \\
\hline & Source & China statistical yearbook & & \\
\hline \multirow[t]{3}{*}{ Capital } & Definition & $\begin{array}{l}\text { Net value of capital stock of } 3 \text { sectors (agriculture, } \\
\text { industry, and service sector) }\end{array}$ & 16,461 & 13,019 \\
\hline & Unit & 100 million yuan & & \\
\hline & Source: & Shan 2008 [24] & & \\
\hline \multirow{3}{*}{$\begin{array}{l}\text { Gross regional } \\
\text { product (GRP) }\end{array}$} & Definition & GRP of 3 sectors (agriculture, industry, and service sector) & 8,342 & 7,209 \\
\hline & Unit & 100 million yuan & & \\
\hline & Source & China statistical yearbook & & \\
\hline \multirow[t]{3}{*}{ Waste gas } & Definition & Waste gas of industry sector & 11,468 & 9,144 \\
\hline & Unit & 100 million $\mathrm{m}^{3}$ & & \\
\hline & Source & China statistical yearbook & & \\
\hline \multirow[t]{3}{*}{ Wastewater } & Definition & Waste water of industry sector and household sector & 183,665 & 143,230 \\
\hline & Unit & 10 thousand tons & & \\
\hline & Source & China statistical yearbook & & \\
\hline \multirow[t]{3}{*}{ Patients } & Definition & Sum of inpatient and outpatient number & 8,845 & 6,769 \\
\hline & Unit & 10 thousands of person & & \\
\hline & Source & China health statistical yearbook & & \\
\hline \multirow[t]{3}{*}{ Infectious diseases } & Definition & Sum of 21 types of infectious diseases case number & 110,914 & 69,943 \\
\hline & Unit & 1 person & & \\
\hline & Source & China health statistical yearbook & & \\
\hline
\end{tabular}

2. Capital: To represent capital, we use the net values of capital stock in three sectors (agriculture, industry, and service). These values are deflated to 2005 price levels using the consumer price index (CPI) obtained from CSY. We built capital stock data referring previous research [24].

3. GRP: In China, the GDP has been widely used to evaluate a region's growth in terms of production values and economic growth for all levels of government performance evaluations [12]. In this study, we use GRP, as regional GDP, in three sectors (agriculture, industry, and service). The CPI is used to deflate this data series to 2005 price levels.

4. Waste gas: We use waste gas emissions only from the industrial sector; these data series represent environmental pollution.

5. Wastewater: We use wastewater quantities from both the industrial sector and the household sector. These data series also represent environmental pollution.

6. Patients: We use the sum of inpatient (i.e., emergency room visits) and outpatient (i.e., hospital admissions) visits to health care facilities as a proxy for the public health level of a region.

7. Infectious disease: We use the sum of the cases of 21 types of infectious disease that are included in the notifiable diseases that are identified by the Chinese Ministry of Health. This factor is considered to be an indicator of the level of infectious diseases (see Additional file 1). 
The selection of independent variables reflects both the results of previous studies and data availability. All of the examined data are obtained from the CSY at the provincial level (see Table 2).

1. FDI: We examine the quantity of foreign direct investment (FDI) and expect that FDI would negatively affect aggregate productive inefficiency but positively affect inefficiencies that relate to environmental pollution emission and public health. This phenomenon is expected to occur because $R \& D$, advanced management techniques, and high-efficiency technologies might be transferred with FDI. These improvements may contribute to a decrease in productive inefficiency. However, we expect that the pollution haven effect may become more evident during the course of this analytical step, which examines the quantity of FDI. In addition, pollution emissions that are related to FDI may increase the risks of disease.

Table 2 Summary of variables for panel tobit model

\begin{tabular}{|c|c|}
\hline \multicolumn{2}{|l|}{ Variables for panel tobit model } \\
\hline \multicolumn{2}{|l|}{ Foreign direct investment (FDI) } \\
\hline Definition & Foreign direct investment \\
\hline Unit & 100 million yuan \\
\hline Source & China statistical yearbook \\
\hline \multicolumn{2}{|l|}{ Average years of schooling } \\
\hline Definition & Average years of schooling for age $6+$ \\
\hline Unit & Year \\
\hline Source & China statistical yearbook \\
\hline \multicolumn{2}{|l|}{ Pollution abatement investment } \\
\hline Definition & The amount of pollution abatement investment \\
\hline Unit & 100 million yuan \\
\hline Source & Ministry of environmental protection \\
\hline \multicolumn{2}{|l|}{ Private medical expenditures } \\
\hline Definition & Private medical expenditures per capita \\
\hline Unit & Yuan \\
\hline Source & China statistical yearbook \\
\hline \multicolumn{2}{|c|}{ Private medical expenditures with an east regional dummy } \\
\hline Definition & $\begin{array}{l}\text { Private medical expenditures per capita with an east } \\
\text { regional dummy }\end{array}$ \\
\hline Unit & Yuan \\
\hline Source & China statistical yearbook \\
\hline \multicolumn{2}{|c|}{ Dependent variables (results from WRDDM estimation in step 1) } \\
\hline \multicolumn{2}{|l|}{ Aggregate productive inefficiency } \\
\hline \multicolumn{2}{|l|}{ Inefficiency of labor } \\
\hline \multicolumn{2}{|l|}{ Inefficiency of capital } \\
\hline \multicolumn{2}{|l|}{ Inefficiency of GRP } \\
\hline \multicolumn{2}{|l|}{ Inefficiency of waste gas } \\
\hline \multicolumn{2}{|l|}{ Inefficiency of wastewater } \\
\hline \multicolumn{2}{|l|}{ Inefficiency of patients } \\
\hline Inefficiency of infectious diseases & \\
\hline
\end{tabular}


2. Average years of schooling: The average number of years of schooling of the portion of the population that is more than 6 years old is defined as the educational level. We expect this factor to negatively affect aggregate productive inefficiency and GDP because the education of laborers may contribute to human capital.

3. Pollution abatement investment: The quantity of investment in pollution abatement can be regarded as an instrument for environmental protection. Therefore, we expect this factor to negatively affect inefficiencies from waste gas and wastewater.

4. Private medical expenditures: Private health expenditures play a more important role than public hospital services in reducing regional disparities in health conditions in China. Therefore, we examine the quantities of private medical expenditures and expect that these expenditures may negatively affect inefficiencies in the patient and infectious disease variables.

5. Private medical expenditures with an east regional dummy: We also use an east regional dummy variable in the context of assessments of private medical expenditures. One reason for utilizing this dummy variable is that poor living conditions are related to a higher risk of disease. Another reason for this dummy variable is that productive inefficiency scores at the provincial level demonstrate great regional disparities across the 29 examined areas, particularly between the eastern and western areas of China.

The dependent variables for the panel tobit model are the results from step 1 (i.e., WRDDM analysis). In particular, they are the aggregate productive inefficiency scores and the inefficiency score for each of the following individual indicators: labor, capital, GRP, waste gas emissions, wastewater discharge, the total number of patients, and infectious diseases. All of the inefficiency scores range from 0 to 1 except for the inefficiency score of GRP. This score can be greater than 1 because it reflects the degree of expansion.

Due to missing values for infectious diseases in 2004 in WRDDM analysis from step 1, we used only the inefficiency scores from 2005 to 2009 as independent variables. Furthermore, to determine the dependent variables that were related to average years of schooling and private medical expenditures, we also used data from 2005 to 2009. However, for the other two dependent variables, FDI and pollution abatement investment, we used data from 2004 to 2008 to reflect a 1-year time lag.

\section{Results and discussion}

\subsection{Results for the inefficiency estimation by WRDDM}

In step 1, we estimate the productive inefficiency score of each area in China from 2003 and 2005 to $2009 .^{2}$ In addition to the productive inefficiency score, we also estimate the individual inefficiency score for each of the other variables. These variables are labor, capital, GRP, waste gas emissions, wastewater discharge, the total number of patients, and infectious diseases.

First, we calculated the aggregate productive inefficiency score from 2003 to 2009 at the provincial level (see Fig. 1). We described the map of mainland of China to identify the provincial location (see Additional file 2). 


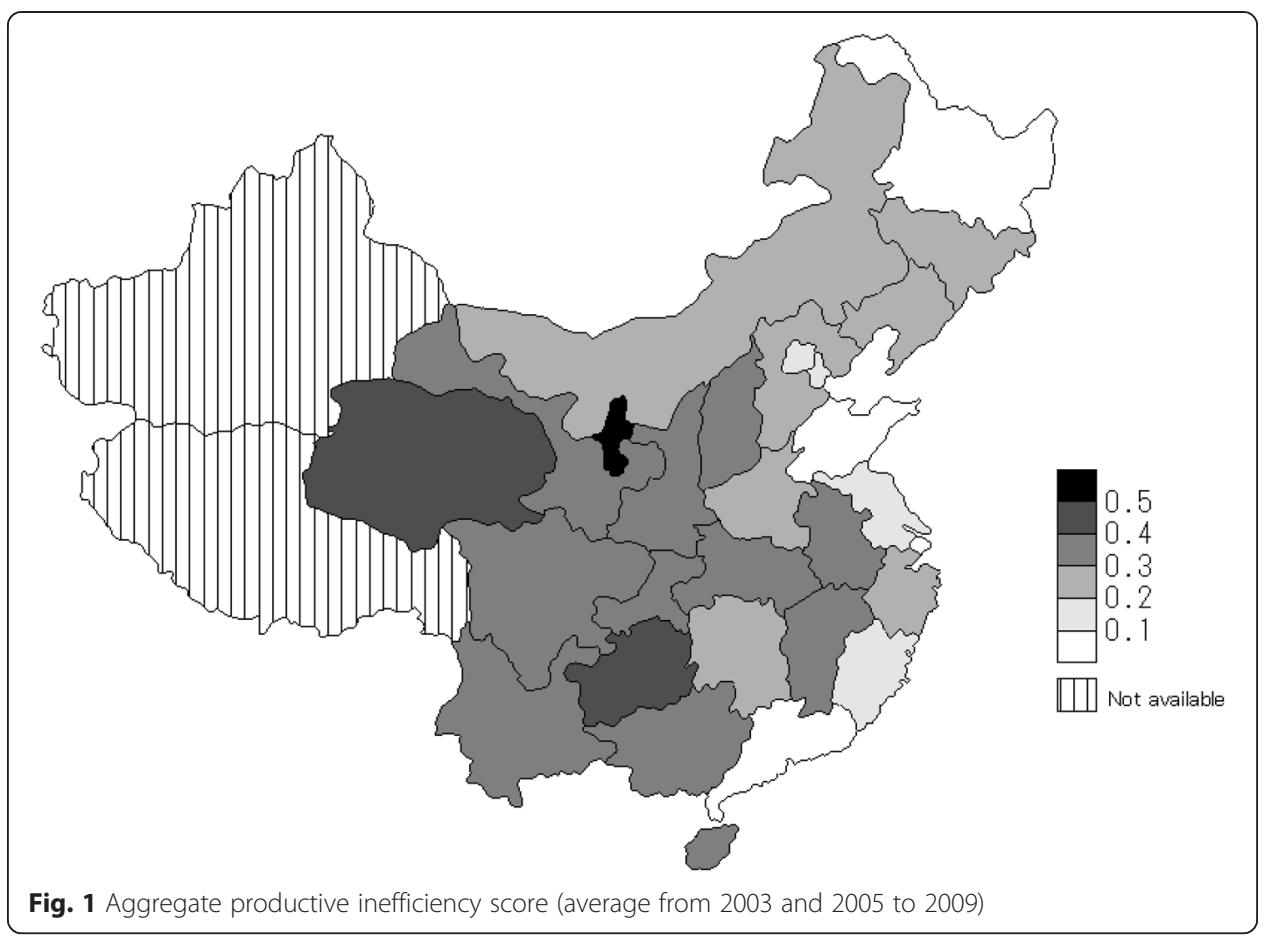

The results of WRDDM analysis with pooled data are presented in Fig. 1. The eastern region of China displays relatively low level of inefficiency (i.e., better productive efficiency), whereas the western region of China displays a relatively high level of inefficiency (i.e., worse productive efficiency). The gap between these two regions is growing over time. Therefore, the assessment of productive inefficiency at the provincial level confirms the perception of great regional disparities among the 29 areas. These disparities are reflected in the discrepancies between the eastern and western areas of China.

We then calculated the aggregate productive inefficiency and the inefficiency for each individual sector at the national level for each year from 2003 to 2009. These calculations display changes in productive inefficiency during the examined years. These results indicate that at the national level, the inefficiency score is decreasing, indicating that the social welfare of China as a whole has improved from 2003 and 2009 (see Fig. 2).

At the national level, the individual inefficiency scores for waste gas, wastewater, and infectious diseases are decreasing, demonstrating that waste gas emission, wastewater discharge, and infectious disease prevention have improved during the examined years. However, at the national level, the inefficiency score with respect to the number of patients decreased from 2003 to 2005 and increased from 2006 to 2009. We also calculate the productive inefficiency scores at the provincial level, and the results of these calculations are shown (see Table 3).

In Table 3, the mean ${ }^{\text {year }}$ is the average inefficiency score of each area from 2003 to 2009. Based on this metric, the following five regions were the most efficient areas that were assessed: Guangdong, Shandong, Heilongjiang, Shanghai, and Beijing. All of these areas lie in the eastern region of China. By contrast, the three least efficient areas were 


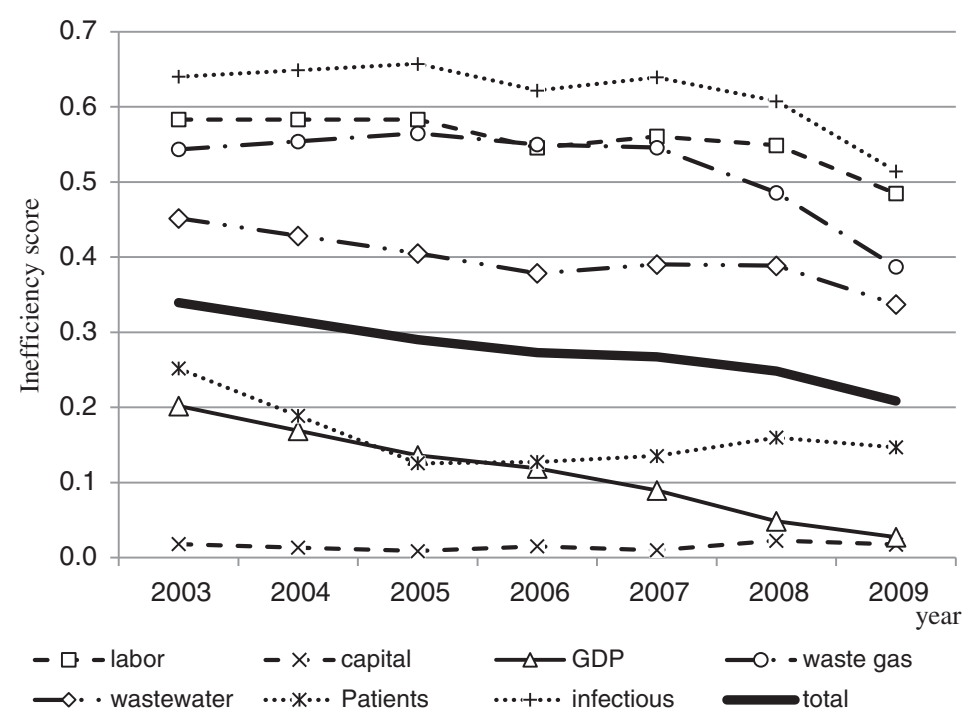

Note: Infectious diseases data in 2004 is missing value. However, we use the mean value of infectious diseases in 2003 and 2005 as value in 2004.

Fig. 2 Inefficiency score of each variables (29 provincial average score)

Ningxia, Qinghai, and Guizhou, all of which are in the western region of China. This result is indicative of the regional disparities that exist among the 29 areas, particularly between the eastern and western portions of China. In Table 3, we define the mean ${ }^{\text {area }}$ as the average inefficiency score across the 29 areas, i.e., the national inefficiency score for each year. This metric illustrates the degree to which productive inefficiency shifted during these years.

We perform various robustness assessments by adding or dropping undesirable output variables. These assessments confirm the results above. First, we calculate the inefficiency score without considering the environmental factors (see Additional file 3). Subsequently, we calculate the score without considering the health factors (see Additional file 4). Finally, we calculate the score without any of the undesirable outputs (see Additional file 5). The correlation coefficients between Table 3 and Additional files 3, 4 , and 5 are $0.980,0.929$, and 0.898 , respectively. These correlation coefficients suggest that the estimates of productive inefficiency performance are nearly identical under the conditions of the various robustness assessments. Thus, the results from Table 3 are plausible and robust.

We estimate the potential rates of aggregate productive inefficiency and of the inefficiency of each individual indicator. These rates can be defined as follows:

1. A percentage by which the relative quantity of inputs (i.e., labor and capital) and undesirable outputs (i.e., waste gas, wastewater, number of patients, and infectious diseases) may be reduced.

2. A percentage by which desirable outputs (i.e., GRP) may be increased.

3. The period of interest is from 2003 to 2009 . However, 2004 is not included due to missing values in the infectious disease data. The results are calculated at the national and provincial levels, as presented in Table 4. 
Table 3 Aggregate productive inefficiency score at the provincial level

\begin{tabular}{|c|c|c|c|c|c|c|c|}
\hline Year & 2003 & 2005 & 2006 & 2007 & 2008 & 2009 & Mean year \\
\hline 01 Beijing & 0.32 & 0.15 & 0.15 & 0.11 & 0.07 & 0.00 & 0.13 \\
\hline 02 Tianjin & 0.28 & 0.18 & 0.16 & 0.15 & 0.11 & 0.00 & 0.15 \\
\hline 03 Hebei & 0.31 & 0.24 & 0.23 & 0.25 & 0.24 & 0.25 & 0.25 \\
\hline 04 Shanxi & 0.38 & 0.29 & 0.29 & 0.28 & 0.27 & 0.29 & 0.3 \\
\hline 05 Inner Mongolia & 0.32 & 0.25 & 0.25 & 0.23 & 0.16 & 0.00 & 0.2 \\
\hline 06 Liaoning & 0.25 & 0.23 & 0.22 & 0.23 & 0.23 & 0.11 & 0.21 \\
\hline 07 Jilin & 0.31 & 0.28 & 0.28 & 0.27 & 0.27 & 0.25 & 0.28 \\
\hline 08 Heilongjiang & 0.10 & 0.00 & 0.00 & 0.13 & 0.08 & 0.18 & 0.08 \\
\hline 09 Shanghai & 0.24 & 0.13 & 0.10 & 0.05 & 0.06 & 0.00 & 0.1 \\
\hline 10 Jiangsu & 0.26 & 0.23 & 0.20 & 0.18 & 0.13 & 0.00 & 0.17 \\
\hline 11 Zhejiang & 0.30 & 0.27 & 0.25 & 0.23 & 0.22 & 0.19 & 0.24 \\
\hline 12 Anhui & 0.34 & 0.33 & 0.33 & 0.33 & 0.32 & 0.28 & 0.32 \\
\hline 13 Fujian & 0.18 & 0.23 & 0.21 & 0.17 & 0.17 & 0.10 & 0.18 \\
\hline 14 Jiangxi & 0.34 & 0.33 & 0.32 & 0.32 & 0.31 & 0.27 & 0.32 \\
\hline 15 Shandong & 0.24 & 0.14 & 0.00 & 0.05 & 0.00 & 0.00 & 0.07 \\
\hline 16 Henan & 0.33 & 0.29 & 0.28 & 0.29 & 0.28 & 0.29 & 0.3 \\
\hline 17 Hubei & 0.32 & 0.34 & 0.33 & 0.31 & 0.29 & 0.26 & 0.31 \\
\hline 18 Hunan & 0.34 & 0.31 & 0.29 & 0.28 & 0.26 & 0.18 & 0.28 \\
\hline 19 Guangdong & 0.00 & 0.00 & 0.00 & 0.02 & 0.06 & $0 . .00$ & 0.01 \\
\hline 20 Guangxi & 0.42 & 0.38 & 0.37 & 0.37 & 0.36 & 0.36 & 0.38 \\
\hline 21 Hainan & 0.41 & 0.43 & 0.40 & 0.35 & 0.33 & 0.30 & 0.37 \\
\hline 22 Chongqing & 0.40 & 0.38 & 0.39 & 0.38 & 0.36 & 0.30 & 0.37 \\
\hline 23 Sichuan & 0.42 & 0.39 & 0.38 & 0.38 & 0.35 & 0.31 & 0.37 \\
\hline 24 Guizhou & 0.52 & 0.43 & 0.43 & 0.42 & 0.39 & 0.34 & 0.42 \\
\hline 25 Yunnan & 0.41 & 0.38 & 0.38 & 0.38 & 0.34 & 0.34 & 0.37 \\
\hline 26 Shanxi & 0.44 & 0.37 & 0.33 & 0.32 & 0.32 & 0.28 & 0.34 \\
\hline 27 Gansu & 0.48 & 0.38 & 0.36 & 0.35 & 0.35 & 0.35 & 0.38 \\
\hline 28 Qinghai & 0.50 & 0.47 & 0.48 & 0.43 & 0.43 & 0.41 & 0.45 \\
\hline 29 Ningxia & 0.68 & 0.57 & 0.52 & 0.48 & 0.47 & 0.42 & 0.52 \\
\hline Mean ${ }^{\text {area }}$ & 0.34 & 0.29 & 0.27 & 0.27 & 0.25 & 0.21 & \\
\hline Standard deviation & 0.127 & 0.127 & 0.131 & 0.118 & 0.121 & 0.137 & \\
\hline
\end{tabular}

Mean $^{\text {year }}$ represents average inefficiency score of each area in 2003 and 2005 to 2009 . Mean ${ }^{\text {area }}$ shows average inefficiency score of each year, among 29 areas (i.e., national inefficiency score)

At the national level, the productive potential rates of capital and GRP are 0.012 and 0.025 , respectively. At the aggregate level, the potential for reducing capital inputs and the potential for expanding GRP are both relatively small compared with the potentials of other factors. For instance, the productive potential rate of labor is 0.565 , implying that over the entire country, labor can be reduced by $56.5 \%$ without slowing economic growth.

There are two types of undesirable environmental outputs: waste gas and wastewater. At the national level, the productive potential rate of waste gas is 0.507 , whereas the productive potential rate of wastewater is 0.377 . Therefore, over the entire country, waste gas can be reduced by $50.7 \%$ without slowing economic growth, and similarly, wastewater can be reduced by $37.7 \%$. This result demonstrates that at the aggregate 
Table 4 Potential amount of improvement by type of variables

\begin{tabular}{|c|c|c|c|c|c|c|c|}
\hline & Labor & Capital & GRP & Waste gas & Wastewater & Patient & $\begin{array}{c}\text { Infectious } \\
\text { disease }\end{array}$ \\
\hline Unit & 10 thousand & $\begin{array}{c}100 \text { million } \\
\text { yuan }\end{array}$ & $\begin{array}{c}100 \text { million } \\
\text { yuan }\end{array}$ & $\begin{array}{c}100 \text { million } \\
\mathrm{m}^{3}\end{array}$ & $\begin{array}{l}10 \text { thousand } \\
\text { tons }\end{array}$ & $\begin{array}{c}10 \text { thousand } \\
\text { persons }\end{array}$ & 1 person \\
\hline 01 Beijing & 259 & 1,695 & 0 & 158 & 20,196 & 1,116 & 25,320 \\
\hline 02 Tianjin & 114 & 102 & 0 & 1,753 & 16,771 & 451 & 12,778 \\
\hline 03 Hebei & 2,300 & 0 & 0 & 27,434 & 78,596 & 286 & 79,283 \\
\hline 04 Shanxi & 1,071 & 3 & 47 & 15,577 & 47,184 & 499 & 60,191 \\
\hline $\begin{array}{l}05 \text { Inner } \\
\quad \text { Mongolia }\end{array}$ & 511 & 143 & 0 & 8,375 & 13,206 & 125 & 36,839 \\
\hline 06 Liaoning & 991 & 110 & 0 & 14,084 & 108,886 & 15 & 41,995 \\
\hline 07 Jilin & 739 & 1,073 & 0 & 2,220 & 54,254 & 693 & 43,339 \\
\hline 08 Heilongjiang & 364 & 0 & 0 & 906 & 11,400 & 0 & 26,359 \\
\hline 09 Shanghai & 132 & 140 & 0 & 1,717 & 61,188 & 764 & 10,998 \\
\hline 10 Jiangsu & 1,647 & 0 & 0 & 9,045 & 214,247 & 404 & 36,399 \\
\hline 11 Zhejiang & 1,779 & 418 & 0 & 7,690 & 143,200 & 4,252 & 104,652 \\
\hline 12 Anhui & 2,827 & 0 & 0 & 8,190 & 81,264 & 2,401 & 100,700 \\
\hline 13 Fujian & 859 & 0 & 0 & 1,763 & 99,322 & 115 & 52,466 \\
\hline 14 Jiangxi & 1,619 & 297 & 0 & 3,840 & 71,909 & 1,400 & 81,996 \\
\hline 15 Shandong & 1,103 & 0 & 0 & 3,368 & 26,724 & 6 & 17,297 \\
\hline 16 Henan & 4,356 & 0 & 0 & 10,372 & 128,969 & 2,623 & 229,598 \\
\hline 17 Hubei & 1,927 & 515 & 54 & 7,187 & 142,399 & 1,952 & 125,110 \\
\hline 18 Hunan & 2,755 & 0 & 0 & 3,475 & 140,476 & 891 & 81,483 \\
\hline 19 Guangdong & 136 & 0 & 0 & 344 & 22,007 & 465 & 10,786 \\
\hline 20 Guangxi & 1,962 & 0 & 776 & 7,265 & 194,122 & 2,583 & 108,649 \\
\hline 21 Hainan & 248 & 270 & 260 & 506 & 17,865 & 212 & 19,625 \\
\hline 22 Chongqing & 1,297 & 0 & 441 & 4,848 & 92,111 & 1,438 & 69,280 \\
\hline 23 Sichuan & 3,495 & 418 & 1,443 & 8,106 & 115,904 & 5,773 & 188,432 \\
\hline 24 Guizhou & 1,837 & 0 & 826 & 4,961 & 8,639 & 595 & 97,180 \\
\hline 25 Yunnan & 2,068 & 0 & 660 & 4,216 & 24,718 & 2,761 & 81,683 \\
\hline 26 Shanxi & 1,439 & 685 & 431 & 3,358 & 36,875 & 1,372 & 77,129 \\
\hline 27 Gansu & 1,069 & 0 & 305 & 3,784 & 12,515 & 1,544 & 105,053 \\
\hline 28 Qinghai & 177 & 0 & 319 & 1,583 & 7358 & 246 & 20,702 \\
\hline 29 Ningxia & 159 & 0 & 537 & 2,587 & 17,005 & 224 & 16,059 \\
\hline $\begin{array}{l}29 \text { area } \\
\text { potential total }\end{array}$ & 39,237 & 5,867 & 6,100 & 168,713 & $2,009,310$ & 35,207 & $1,961,380$ \\
\hline $\begin{array}{l}29 \text { area data } \\
\text { total }\end{array}$ & 69,487 & 477,393 & 241,944 & 332,584 & $5,326,304$ & 256,491 & $3,216,494$ \\
\hline Potential rate & $56 \%$ & $1.2 \%$ & $2.5 \%$ & $51 \%$ & $38 \%$ & $13.7 \%$ & $61 \%$ \\
\hline
\end{tabular}

Twenty-nine area potential total represents the sum of potential among 29 areas from 2003 and 2005 to 2009 . Twenty-nine area data total shows the sum of data value among 29 areas from 2003 and 2005 to 2009 . Potential rate is calculated by 29 area potential total divided by 29 area data total. The unit of patients was " 1 person" in WRDDM estimation process. But in this table, we changed it into " 10 thousand people", for easy reading

level, a greater potential for progress exists for waste gas reduction than for wastewater treatment. Therefore, the government should invest more resources into waste gas reduction than wastewater treatment.

Recall that the "number of patients" is defined as the sum of outpatient (i.e., hospital admissions number) and inpatient (i.e., emergency room visits) hospital visits for a 
region. The "infectious diseases" factor is defined to be the total number of cases of 21 different types of infectious disease.

According to the analytical results, at the national level, the productive potential rate of the number of patients is 0.137 , whereas the productive potential rate of infectious diseases is a much higher value of 0.61 . Therefore, there is a much higher potential for reducing the number of cases of infectious disease than for reducing the total number of patients.

Motivated by this result, we suggest that government should not only focus on GRP growth and capital expansion but also address issues of environmental protection and public health quality. In particular, there appear to be large potential gains in terms of waste gas reduction and infectious disease prevention.

\subsection{Results for determinant analyses by the panel tobit Model}

We analyze certain external factors that could be considered to be related to inefficiency. In this analysis, we consider both aggregate productive inefficiency and the inefficiency of each individual sector. We attempt to determine the factors that influence these inefficiencies. The results of this analysis are shown below.

From Table 5, the results of the analysis indicate that FDI negatively affects aggregate productive inefficiency but positively affects the inefficiencies of capital, waste gas, and the number of patients. It can be shown that FDI contributed to improvements in productive inefficiency. One possible driver of these contributions is that FDI is accompanied by an influx of advanced technologies and production processes into a country. This influx may have caused FDI to enhance overall productive efficiency in China.

Concurrently, the FDI results may also indicate that higher FDI produced increased pollution emissions. There are three possible reasons why we obtained this result. Firstly, the FDI in China has primarily been concentrated in the manufacturing sector, which generates much greater pollution than the agricultural or service sectors. Secondly, variation in environmental standards across different regions encourages both local firms and FDI to move their factories to locations where regulations are less stringent [20]. Thirdly, the implementation of environmental regulations is largely dependent on local government and officials. Both local firms and firms that are funded through FDI can emit pollutants beyond the official allowable level if they bribe local Chinese officials [25].

Given the results for FDI, we suggest that the Chinese government should examine FDI in manufacturing industries, particularly in the context of industries that are associated with large quantities of waste gas emission. Second, environmental regulations should be rigorous and consistent across different regions over the long term. Finally, although a reduction of manufacturing efforts is important, the implementation of environmental regulation by local officials should not be ignored.

The metric of average years of schooling is not statistically significant for any of the types of inefficiency scores. This result suggests that education level may have no impact on waste gas and wastewater emission. The reason for this lack of impact may be that most of the waste gas and wastewater that are produced in China are emitted by the industrial sector. This sector is not influenced by personal decision-making.

With respect to human health indicators, we find that education level does not have a significant impact on the number of patients or the number of cases of infectious 
Table 5 Result of panel tobit model

\begin{tabular}{|c|c|c|c|c|c|c|c|c|}
\hline & Model 1 & Model 2 & Model 3 & Model 4 & Model 5 & Model 6 & Model 7 & Model 8 \\
\hline & Productive inefficiency & Labor & Capital & GRP & Waste gas & Wastewater & Patients & Infectious diseases \\
\hline FDI & $-7.00 \mathrm{E}-06^{* *}$ & $1.50 \mathrm{E}-06$ & $3.00 \mathrm{E}-05^{* * *}$ & $1.00 \mathrm{E}-05$ & $3.00 \mathrm{E}-05^{* *}$ & $-1.00 \mathrm{E}-06$ & $4.00 \mathrm{E}-05^{* * *}$ & $\begin{array}{l}-6.00 \mathrm{E}-06 \\
\end{array}$ \\
\hline Average years of schooling & $-2.00 \mathrm{E}-02$ & $3.90 \mathrm{E}-02$ & $-5.00 \mathrm{E}-02$ & $-3.00 \mathrm{E}-01$ & 4.00E-03 & $1.00 \mathrm{E}-01$ & 7.00E-02 & $8.00 \mathrm{E}-02$ \\
\hline Pollution abatement investment & $-2.00 \mathrm{E}-05$ & $-2.00 \mathrm{E}-04$ & $-1.00 \mathrm{E}-04$ & 1.00E-03 & 6.00E-04 & $-9.00 \mathrm{E}-05$ & $-2.00 \mathrm{E}-05$ & $-4.00 \mathrm{E}-05$ \\
\hline Private medical expenditures & $-1.00 \mathrm{E}-04^{* * *}$ & $-1.20 \mathrm{E}-04$ & $3.00 \mathrm{E}-04^{* * *}$ & $-8.00 \mathrm{E}-04^{* *}$ & $-4.00 \mathrm{E}-04^{* * *}$ & $-1.00 \mathrm{E}-04$ & $-4.00 \mathrm{E}-05$ & $-2.00 \mathrm{E}-04^{*}$ \\
\hline Eastern private medical expenditures & $3.00 \mathrm{E}-06$ & $-2.60 \mathrm{E}-04^{* *}$ & $-5.00 \mathrm{E}-04^{* * *}$ & $-4.00 \mathrm{E}-03^{*}$ & $-5.00 \mathrm{E}-04^{* * *}$ & $-3.00 \mathrm{E}-04^{* * *}$ & $-2.00 \mathrm{E}-04$ & $-4.00 \mathrm{E}-04^{* * *}$ \\
\hline Log likelihood & 290.62 & 111.68 & 35.72 & 20.89 & 79.21 & 98.02 & 78.03 & 98.1 \\
\hline
\end{tabular}

Number of Observations, 145. DI and pollution abatement investment are applied with 1-year time lag. Eastern private medical expenditures is defined by private medical expenditure multiplied eastern province dummy

$* * * * *$, and * indicate the coefficient of significance at the 1,5 , and $10 \%$ levels 
diseases. This result might reflect the fact that human health (i.e., the number of patients) is primarily affected by lifestyle choices, which change with economic growth. In particular, infectious diseases are primarily caused by poor public infrastructure, such as inadequate access to water sanitation facilities, and depend on individuals' quality of access to private health care. Economic growth also enhances society's ability to construct infrastructure for water sanitation.

Pollution abatement investments are not statistically significant for any of the types of inefficiency scores that are examined. This result indicates that a large quantity of pollution abatement investment decreases capital productivity in manufacturing sectors. One of the reasons for this effect may be that legal considerations involving environmental regulations caused many factories to purchase a large quantity of pollution treatment equipment. However, due to the weakness of regulation implementation in China, these factories only use the abatement equipment during certain specific moments known as a "show". This practice allows the factories in question to reduce their operational costs of running the equipment. Another reason for the lack of a significant relationship between pollution abatement investments and inefficiency scores may be that our data only reflect the quantity of investments that were devoted to end-of-pipe treatments. Although end-of-pipe treatment equipment directly affects pollution reduction, it does not directly affect the total amount of pollution emissions. This result suggests that environmental regulations and the monitoring of pollutant emissions should be more strictly implemented in China.

Private medical expenditures produce adverse effects on aggregate productive inefficiency, GRP, waste gas, and the cases of infectious diseases, although these expenditures positively affect the inefficiency of capital. The effects of this factor are statistically significant for waste gas but not for wastewater. In addition, private medical expenditures produce statistically significant effects on the number of cases of infectious diseases but insignificant effects on the total number of patients.

These results reveal that private medical expenditures are the main driver of the inefficiency of infectious diseases. The reason for this phenomenon may be that infectious disease incidences are directly related to private health care, whereas overall public health is affected by lifestyle. In addition, the medical insurance system, which helps individuals hedge against the risk of incurring medical expenses, contributes to private medical expenditures. It is notable that as an aspect of healthcare reform, the Chinese government attempts to provide complete medical insurance for more of its citizens.

We now consider the analysis that uses private medical expenditures combined with an east regional dummy. We find that in this situation, medical expenditures adversely affect the inefficiencies of labor, capital, GRP, waste gas, wastewater, and the number of cases of infectious diseases. However, this effect is not statistically significant for either aggregate productive inefficiency or the total number of patients.

In Model 8 of the panel tobit model, we considered the factors that influence the inefficiencies that relate to cases of infectious disease. The model results indicated that the coefficient of private medical expenditure is $-2.00 \mathrm{E}-04$, whereas the coefficient of private medical expenditures with an east regional dummy included is $-4.00 \mathrm{E}-04$. Thus, 
private medical expenditure produces stronger influences in the eastern region of China than in the western region of China.

Motivated by these results, we suggest that the local government should devote more attention to infectious diseases than to other general diseases. We also suggest that to reduce regional disparity, the medical insurance system should provide more support for the western residents of China.

\section{Conclusions}

We analyze productive inefficiencies, considering both environmental pollution and health impacts. Our results indicate that aggregate productive inefficiencies improved from 2003 to 2009 on both a national level and a provincial level. However, the regional disparities in aggregate productive inefficiency have increased. In particular, the gap in productive inefficiencies between the eastern regions and western regions of China has widened.

Furthermore, we find that the productive potential is large, particularly with respect to waste gas emissions and cases of infectious diseases. We suggest that the government should focus on environmental protection and public health preservation. In particular, efforts to reduce waste gas emission and prevent infectious disease could greatly improve social welfare.

In addition, we estimate the determinants of aggregate productive inefficiency. We find that FDI and private medical expenditures contribute to the improvement of aggregate productive inefficiency in China. FDI negatively affects aggregate productive inefficiency but positively affects the inefficiencies of waste gas emission and public health considerations. Private medical expenditures negatively affect aggregate productive inefficiency, waste gas emission, and infectious disease prevention. Furthermore, a stronger impact on productive inefficiency was produced by local governments in the eastern region of China than by the governments in the western region of China.

Finally, we suggest that the government should focus on FDI and private medical expenditures to attain economic development that involves lower pollution levels and fewer health problems. In addition, preferential policies towards private medical care should provide support to western Chinese residents, narrowing the large gap across regions. Environmental policymaking should be rigorous and consistent. Moreover, these policies should be strictly enforced.

One major limitation of the study is that we did not consider the different industry structures across the agricultural, industry, and service sectors. This concern is relevant because the different sectors produce different impacts on the emission of environmental pollutants and the resulting damage to human health. Furthermore, the eastern region and the western region of China demonstrate large differences in industrial structure.

\section{Endnotes}

${ }^{1}$ The coefficient 0.962 is the ratio of labor in year 2006 in the CSY to labor in year 2006 in the CSDM60, as calculated by authors. This correction factor reflects the small differences between CSDM60 and CSY.

${ }^{2}$ Xinjiang, Tibet, Hong Kong, and Macau are not included due to missing data. The results for 2004 are not included because of missing values in the infectious disease data. 


\section{Additional files}

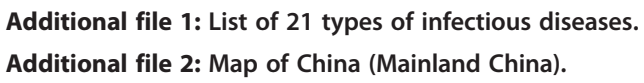

\section{Competing interests}

The authors declare that they have no competing interests.

\section{Authors' contributions}

Cao Huijuan builds dataset and analyze productivity score. Hidemichi Fujii makes introduction and consider the results and conclusion. Shunsuke Managi develops the story of this paper and considers the productivity estimation results.

\section{Acknowledgement}

This research was funded by the Grant-in-Aid for Specially Promoted Research 26000001B), The Ministry of Education, Culture, Sports, Science and Technology (MEXT), Japan, and Grant-in-Aid for Research Activity Start-up 26881006B), MEXT, Japan. The results and conclusions of this article do not necessary represent the views of the funding agencies.

\section{Author details}

${ }^{1}$ Graduate School of Environmental Studies, Tohoku University, 6-6-20 Aramaki-Aza AobaAoba-Ku, Sendai 980-8579, Japan. ${ }^{2}$ Graduate School of Fisheries Science and Environmental Studies, Nagasaki University, 1-14 Bunkyo-machi, Nagasaki 852-8521, Japan. ${ }^{3}$ Global Environmental Engineering Program, School of Engineering, Kyushu University, 744 Motooka Nishi-ku, Fukuoka 819-0395, Japan. ${ }^{4}$ Queensland University of Technology, Level 8, Z Block, Gardens Point, 2 George St, Brisbane QLD 4000, Australia.

Received: 16 December 2014 Accepted: 30 March 2015

Published online: 11 June 2015

\section{References}

1. Liu S, Griffiths SM. From economic development to public health improvement: China faces equity challenges. Public Health. 2011;125(10):669-74.

2. Ullah MS, Inaba K. Liberalization and FDI Performance: evidence from ASEAN and SAFTA member countries. Journal of Economic Structures. 2014;3(6):1-24.

3. Managi S, Kaneko S. Productivity of market and environmental abatement in China. Environmental Economics and Policy Studies. 2006;7:459-70.

4. Fujii $\mathrm{H}$, Cao J, Managi S. Decomposition of productivity considering multi-environmental pollutants in Chinese industrial sector. Rev Dev Econ. 2015;19(1):75-84.

5. Fujii H, Managi S, Kaneko S. Decomposition analysis of air pollution abatement in China: empirical study for ten industrial sectors from 1998 to 2009. J Clean Prod. 2013;59(15):22-31.

6. Li LM, Tang JL, LV J, Jiang Y, Griffiths SM. The need for integration in health sciences sets the future direction for public health education. Public Health. 2011;125(1):20-4.

7. Wang Y. Development of the new rural cooperative medical system in China. China \& World Economy. 2007;15(4):66-77.

8. Lin M, Lee $Y$, Ho T. Applying integrated DEA/AHP to evaluate the economic performance of local governments in China. Eur J Oper Res. 2011;209(2):129-40.

9. Kira M, Nam K, Selin NE, Lamsal LN, Reilly JM, Paltsev S. Health damages from air pollution in China. Glob Environ Chang. 2012;22(1):55-66.

10. Kan H, Chen B. Particulate air pollution in urban areas of Shanghai, China: health-based economic assessment. Sci Total Environ. 2004;322(1-3):71-9.

11. Zhang W, Bansback N, Anis AH. Measuring and valuing productivity loss due to poor health: a critical review. Soc Sci Med. 2011;72(2):1185-192.

12. Nan Y, Gao Y. Statistical and econometric analysis of the impact of China's energy, environment on the economic development. Energy Procedia. 2011;5:2358-62.

13. Kan $\mathrm{H}$, Chen $\mathrm{R}$, Tong $\mathrm{S}$. Ambient air pollution, climate change, and population health in China. Environ Int. 2012:42:10-9.

14. Cao J, Yang C, Li J, Chen R, Chen B, Gu D, et al. Association between long-term exposure to outdoor air pollution and mortality in China: a cohort study. Journal of Hazardous Material. 2011;191(3):1594-600.

15. Lybarger JA, Lee R, Vogt DP, Perhac Jr RM, Spengler RF, Brown DR. Medical costs and lost productivity from health conditions at volatile organic compound-contaminated superfund sites. Environ Res. 1998;79(1):9-19.

16. Zhang C, Zhuang L. The composition of human capital and economic growth: evidence from China using dynamic panel data analysis. China Econ Rev. 2011;22(1):165-71.

17. Sanjeev G, Verhoeven M, Tiongson ER. The effectiveness of government spending on education and healthcare in developing and transition economies. Eur J Polit Econ. 2002;18(4):717-37.

18. Filmer D, Hammer JS, Pritchett LH. Health policy in poor countries: weak links in the chain. Policy Research Working Paper No. 1874. Washington, DC: World Bank; 1998.

19. Lauter M, Moreaub F. Domestic investment and FDI in developing countries: the missing link. J Econ Dev. 2012;37(3):1-23. 
20. Wang DT, Gu FF, Tse DK, Yim CB. When does FDI matter? The roles of local institutions and ethnic origins of FDI. International Business Review. 2013;22(2):450-465.

21. Barros CP, Managi S, Matousek R. The technical efficiency of the Japanese banks: non-radial directional performance measurement with undesirable output. Omega-The International Journal of Management Science. 2012:40(1):1-8

22. Fujii H, Managi S, Matousek R. Indian bank efficiency and productivity changes with undesirable outputs: a disaggregated approach. J Bank Financ. 2014;38(1):41-50.

23. Fujii $\mathrm{H}$, Kaneko S, Managi S. Changes in environmentally sensitive productivity and technological modernization in China's iron and steel industry in the 1990s. Environ Dev Econ. 2010;15(4):485-504.

24. Shan H. Reestimating the capital stock of China: 1952-2006. The Journal of Quantitative \& Technical Economics. 2008;10:17-31.

25. Christmann P, Taylor G. Globalization and the environment: determinants of firm self-regulation in China. J Int Bus Stud. 2001:32(3):439-58.

Submit your manuscript to a SpringerOpen ${ }^{\circ}$ journal and benefit from:

- Convenient online submission

- Rigorous peer review

- Immediate publication on acceptance

- Open access: articles freely available online

- High visibility within the field

- Retaining the copyright to your article

Submit your next manuscript at $>$ springeropen.com 